\title{
Lannoitusvasteet nurmirehuntuotannossa
}

\author{
Mikko Korhonen ${ }^{1)}$, Marketta Rinne ${ }^{2)}$ ja Pekka Huhtanen ${ }^{2)}$ \\ ${ }^{1)}$ Kemira GrowHow Oyj, Mechelininkatu 1a, PL 900, 00181 Helsinki, mikko.korhonen@kemira- \\ growhow.oyj \\ ${ }^{2)}$ MTT, Kotieläintuotannon tutkimus, 31600 Jokioinen, marketta.rinne@mtt.fi,pekka.huhtanen@mtt.fi
}

Nurmen lannoituskokeita on pitkään tehty suomalaisen lannoitevalmistajan (nyk. Kemira GrowHow Oyj) toimesta viljelijöiden pelloilla eri puolilla Suomea. Normaaleissa viljelyolosuhteissa toteutetuissa kokeissa on tutkittu lannoitustason vaikutusta säilörehunurmen (pääasiassa timotei-nurminataseoksia) 1. ja 2. sadon määrään ja laatuun (rehuarvo, kivennäis- ja hivenainepitoisuudet). Kokeet ovat olleet samalla lohkolla kolmen vuoden ajan ja niissä on käytetty tavanomaisia viljelymenetelmiä ja NPKlannoitteita. Kokeissa on selvitetty myös maan kasvukunto viljavuusanalyyseillä. Tässä tutkimuksessa analysoitiin tilastollisesti viimeisten kymmenen vuoden aikana (1995 - 2004, 32 tilaa, 336 havaintoa) tehtyjen nurmikokeiden tulokset SAS MIXED -proseduurilla siten, että yksittäisen kokeen (tila*vuosi) vaikutus saatiin huomioitua. Lineaarisella regressioanalyysillä tarkasteltiin satovastetta, kun lannoitusta muutettiin. Satovasteiden lisäksi aineistosta selvitettiin lannoituksen vaikutus rehun koostumukseen ja sulavuuteen erikseen 1. ja 2. sadon osalta sekä yhdistettynä.

Maanäytteiden perusteella koelohkot olivat keskimäärin luokassa tyydyttävä useimpien mitattujen parametrien osalta, mutta vaihtelu oli suurta. Käytetyt lannoitemäärät hehtaaria kohti olivat keskimäärin ensimmäiselle sadolle 85 kg N (0-144), 12.5 kg P (0-33) ja 25 kg K (0-83) sekä toiselle sadolle 69 kg N (0-130), 8 kg P (0-19.5) ja 23 kg K (0-92) hehtaaria kohti. Keskimääräinen kuiva-aineen (KA) sato yhteensä molemmissa sadoissa oli $6588 \mathrm{~kg}$ (1150-13749), josta 1. sadon osuus oli $52 \%$. Sadon keskimääräinen raakavalkuaispitoisuus oli 152 g/kg KA (66-233, 1. sato 158 2. sato 148) ja D-arvo 664 g/kg KA (582-729, 1. sato 680 ja 2. sato 649). Kun typpilannoitusta lisättiin 1 kg/ha, koko kesän nurmen kuiva-ainesato kasvoi $20.8 \mathrm{~kg} / \mathrm{ha}$. Ensimmäisessä sadossa satovaste typpikiloa kohti oli $17.5 \mathrm{ja}$ 2. sadossa $23.8 \mathrm{~kg} \mathrm{KA} / \mathrm{ha}$. Sadon lisäksi typpilannoituksen lisääminen lisäsi pääsääntöisesti rehun kivennäis- ja hivenainepitoisuuksia.

Aineisto luokiteltiin maalajin ja $\mathrm{pH}: n$ mukaan eri luokkiin. Karkeilla kivennäismailla typpikilolla saatiin $25.8 \mathrm{~kg} \mathrm{KA} / \mathrm{ha}$ (vakio $3244 \mathrm{~kg} / \mathrm{ha}$ ) kun vasteet savimailla ja eloperäisillä mailla olivat 20.4 kg KA/ha ja 18.5 kg KA/ha (vakiot 3731 ja $4845 \mathrm{~kg} / \mathrm{ha}$ ). Maan happamuuden osalta suurin ero satovasteessa ja vakion arvossa oli $\mathrm{pH}$ :n noustessa yli 6.5:n (luokat < 6, 6-6.5 ja >6,5).

Vaihtelu ruohonäytteiden kivennäis- ja hivenainepitoisuuksissa oli suurta, joten niiden analysointi ruokinnansuunnittelun pohjaksi on usein perusteltua. Lannoituskoeaineiston analysointi kokonaisuutena osoittautui hyödylliseksi tavaksi saada laskettua käyttökelpoisia lannoitusvasteita käytännön suositusten ja neuvonnan pohjaksi. Haasteena on mallintaa nurmen kasvu siten, että voitaisiin yhdistää D-arvo, lannoitus ja satotaso, jotta nurmituotantoa voitaisiin optimoida suhteessa ruokintaan ja pellon käyttöön.

Asiasanat: Nurmi, typpi, lannoitus, sato, kivennäisaine, hivenaine

Taulukko. Nurmen satovasteet yhteenlasketuissa 1. ja 2. sadossa, kun typpilannoitusta lisättiin 1 kg.

\begin{tabular}{lcccccccc}
\hline & Vakio & S.E. & P-arvo & $\begin{array}{c}\text { Kulma- } \\
\text { kerroin }\end{array}$ & S.E. & P-arvo & RSME & $\mathrm{R}^{2}$ \\
\hline Kuiva-aine, kg/ha & 3426 & 188.1 & $* * *$ & 20.8 & 0.84 & $* * *$ & 615.7 & 0.88 \\
Raakavalkuainen, g/kg KA & 114 & 2.8 & $* * *$ & 0.246 & 0.0135 & $* * *$ & 10.4 & 0.79 \\
Fosfori, g/kg KA & 2.95 & 0.046 & $* * *$ & 0.001 & 0.0002 & $* * *$ & 0.131 & 0.42 \\
Kalium, g/kg KA & 25.2 & 0.39 & $* * *$ & 0.025 & 0.002 & $* * *$ & 1.76 & 0.58 \\
Magnesium, g/kg KA & 1.67 & 0.066 & $* * *$ & 0.001 & 0.0003 & $* * *$ & 0.146 & 0.32 \\
Kupari, mg/kg KA & 6.0 & 0.23 & $* * *$ & 0.007 & 0.0011 & $* * *$ & 0.67 & 0.40 \\
Mangaani, mg/kg KA & 51.1 & 5.48 & $* * *$ & 0.010 & 0.0156 & & 4.73 & 0.02 \\
Sinkki, mg/kg KA & 26.0 & 0.95 & $* * *$ & 0.04 & 0.005 & $* * *$ & 3.51 & 0.42 \\
\hline
\end{tabular}




\section{Johdanto}

Nurmen lannoituskokeita on maatiloilla tehty suomalaisen lannoitevalmistajan (nyk. Kemira GrowHow Oyj) toimesta useamman kymmenen vuoden ajan. Lähtökohtana on ollut lannoituskokeen suorittaminen normaalissa viljelyolosuhteissa käyttäen tavallisia menetelmiä ja lannoitteita (NPKlannoitteet) viljelijöiden pelloilla. Useimmiten on mitattu lannoitustason, lähinnä typen määrän, ja lannoitteen koostumuksen vaikutusta lohkolta saatavaan satoon ja sadon laatuun (kemiallinen koostumus). Uusimissa kokeissa on tutkittu sadon lisäksi laatua laajemmin määrittämällä D-arvo ja kivennäis- ja hivenainepitoisuudet.

Tuloksia on käytetty markkinoinnin ja neuvonnan apuvälineenä ja lannoitussuositusten ohjeistuksena. Kun kokeissa on lisäksi tutkittu maan kasvukunto viljavuusanalyyseillä, muodostaa yhdistetty aineisto hyvän pohjan lannoitusvaikutusten laajemmalle tarkastelulle. Tämän tutkimuksen tarkoitus oli koota viimeisten kymmenen vuoden aikana tehty nurmikoeaineisto yhteen ja tarkastella sitä kokonaisuutena yksittäisten koetulosten sijaan käyttäen tilastollista analyysiä. Satovasteiden lisäksi aineistosta selvitettiin lannoituksen vaikutusta rehun koostumukseen ja sulavuuteen erikseen 1. ja 2. sadon osalta että yhdistettynä.

\section{Aineisto ja menetelmät}

Aineisto koostuu Kemira GrowHow Oyj:n (ent. Kemira Agro) toteuttamien nurmen maatilakokeiden tuloksista vuosien 1995-2004 aikana. Nurmikokeet on tehty normaaleissa olosuhteissa viljelijöiden pelloilla eri puolilla Suomea. Kasvilajeina oli pääasiassa timoteinurminataseoksia, mutta joillain lohkoilla oli lisäksi puna-apilaa. Koejakso oli useimmiten kolme vuotta, jonka aikana lannoitekäsittelyt pysyivät samana kullakin lohkolla. Tarkastellussa aineistossa oli mukana tulokset 32 eri tilalta ja yksittäisiä viljelyruutuja oli 336. Tässä aineistossa mukana olevat tulokset perustuvat lähinnä typpitasojen vertailuun käyttäen NPK-lannoitteita.

Ennen kokeen alkua jokaiselta koelohkolta otettiin maanäyte, jota käytettiin peruslannoituksen suunnittelun lähtökohtana. Koelohko jaettiin koeruutuihin, joissa eri lannoituskäsittelyt toteutettiin. Lannoituksen typpitasot vaihtelivat 0 ja $144 \mathrm{~kg} \mathrm{~N} / \mathrm{ha}$ välillä ensimmäiselle sadolle ja 0 - $130 \mathrm{~kg}$ N/ha välillä toiselle sadolle. Koska lannoitteena käytettiin NPK-lannoitteita, myös fosforin ja kalin määrät vaihtelivat typpitason ja käytetyn lannoitteen koostumuksen mukaan. Useimmiten koeruudun ala oli esimerkiksi tietyn mittainen lannoitteenlevittimen levyinen kaista.

Normaalit viljelytoimenpiteet tehtiin tilan omalla kalustolla sisältäen säilörehuksi korjuun. Satonäytteet otettiin ensimmäisestä ja toisesta sadosta säilörehun korjuuasteella leikkaamalla kultakin koelohkolta $0.25 \mathrm{~m}^{2}$ kehikolla 3-5 osanäytettä kasvustosta. Saatu rehumassa punnittiin ja leikatun alan perusteella laskettiin sato. Näytteet analysoitiin Valion säilörehun analyysipalvelussa (uusimmat Artturi-analyysin mukaan, NIR-analyysi) sekä Viljavuuspalvelussa (kivennäis- ja hivenaineet). Maanäytteet analysoitiin Viljavuuspalvelussa standardimenetelmin. Kokeista kerättiin sato-, laatu- (rehuanalyysi) ja maan viljavuustiedot sekä sää, korjuuaika, kivennäis- ja hivenpitoisuudet ja lannoitustiedot vuosittain yhteen. Tässä tarkastelussa koko aineiston tulokset analysoitiin tilastollisesti SAS MIXED -proseduurilla siten, että yksittäisen kokeen (tila*vuosi) vaikutus saatiin huomioitua. Lineaarisella regressioanalyysillä tarkasteltiin satovastetta ja rehun koostumusta, kun typpilannoitusta muutettiin.

Taulukko 1. Koelohkojen maanäytteiden tulokset.

\begin{tabular}{lcccc}
\hline & Keskiarvo & Keskihajonta & Minimi & Maksimi \\
\hline $\mathrm{pH}$ & 6.2 & 0.44 & 5.2 & 7.1 \\
Kalsium, mg/l & 1536 & 652.8 & 484 & 3720 \\
Kalium, mg/l & 137 & 65.3 & 6 & 289 \\
Fosfori, mg/l & 14 & 8.3 & 4 & 104 \\
Magnesium, mg/l & 235 & 120.7 & 51 & 618 \\
Boori, mg/l & 0.6 & 0.35 & 0.3 & 1.7 \\
Kupari, mg/l & 4 & 2.3 & 0.4 & 11 \\
Mangaani, mg/l & 29 & 29.2 & 3 & 135 \\
Sinkki, mg/l & 3.9 & 3.24 & 0.7 & 26 \\
Natrium, mg/l & 35 & 21,8 & 8 & 89 \\
Rikki, mg/l & 18 & 4.5 & 9 & 22 \\
\hline
\end{tabular}




\section{Tulokset ja niiden tarkastelu}

Koelohkojen viljavuustietojen (Taulukko 1) perusteella $\mathrm{pH}: n$ ja eri ravinteiden keskiarvot olivat useimmiten luokassa tyydyttävä tai muutaman ravinteen osalta luokassa välttävä. Minimi ja maksimipitoisuuksien väli on kuitenkin suuri osoittaen sen, että lohkot ovat olleet viljavuusluokiltaan hyvinkin erilaisia. Tämä heijastanee myös yleistä vallitsevaa tilannetta nurmea tuottavilla tiloilla. Koelohkojen viljavuudet ja niiden vaihtelu ovat myös yhteneviä koko maata ajatellen, sillä $\mathrm{pH}$ :n keskiarvo Viljavuuspalvelun vuoden 2002 näytteissä oli 6.1 (4.3 - 7.6) (Viljavuuspalvelu 2005). Vastaava vaihtelu fosforin osalta oli 2 - $140 \mathrm{mg} / \mathrm{l}$ keskiarvon ollessa $11.6 \mathrm{mg} / \mathrm{l}$. Myös hiventen osalta vaihtelu ja keskiarvot ovat samansuuntaisia, sillä vuonna 2002 Viljavuuspalvelun mukaan boorinäytteistä $68 \%$, mangaaninäytteistä $70 \%$ ja sinkkinäytteistä $61 \%$ oli luokissa välttävä tai tyydyttävä. Kuparinäytteistä suurin osa on luokassa tyydyttävä (38 \%) ja välttävän ja hyvän osuudet olivat 24 \% ja $26 \%$.

Keskimääräinen kuiva-aineen (KA) sato yhteensä molemmissa sadoissa oli 6588 kg (Taulukko 2) eli kohtuullisen korkea. Ensimmäisen sadon osuus kokonaissadosta oli hieman yli puolet. Sadon keskimääräinen raakavalkuaispitoisuus oli 152 ja D-arvo 664 g/kg KA. Kaikkien ominaisuuksien kivennäis- ja hivenainepitoisuudet mukaan lukien vaihtelu oli varsin suurta kuvastaen mm. lannoituksen, maaperän ominaisuuksien ja vuosittain vaihtelevien ympäristöolosuhteiden vaikutusta. Ensimmäisen sadon D-arvo ja raakavalkuaispitoisuus olivat keskimäärin hieman suurempia kuin toisen sadon. Kivennäis- ja hivenaineiden pitoisuuksissa eri sadoissa ei ollut kovin merkittäviä eroja. Arvot olivat keskimäärin varsin tyypillisiä (vrt. MTT 2004).

Kun typpilannoitusta lisättiin 1 kg/ha, koko kesän nurmen kuiva-ainesato kasvoi 20.8 kg/ha (Taulukko 3). Satovaste tukee hyvin nurmen typpilannoitussuosituksia ja nykyistä käytäntöä, jonka mukaan typpitaso on molemmille sadoille useimmiten $100 \mathrm{~kg} / \mathrm{ha}$. Kuvassa 1 on havainnollistettu yksinkertaisen (fixed) ja mixed-regressiomallin käytön vaikutuksia tuloksiin. Kun tila*vuosivaikutus on huomioitu, pienenee hajonta huomattavasti. Tässä aineistossa fixed- ja mixed-yhtälöiden leikkauspisteet ja kulmakertoimet olivat kohtuullisen samalla tasolla, joten taulukoissa 3 ja 4 on esitetty vain mixed-yhtälöt.

Samoin kuin kuiva-aineen, kaikkien muidenkin komponenttien sadot lisääntyivät typpilannoituksen lisäämisen myötä. Ensimmäisessä sadossa kuiva-aineen satovaste typpikiloa kohti oli jonkin verran pienempi (17.5 kg/ha) kuin 2. sadossa (23.8 kg KA/ha). Myös muiden satokomponenttien vasteet lannoituksen lisäämiselle typpikiloa kohti laskettuna olivat suurempia jälkikasvussa kuin ensimmäisessä sadossa.

Taulukossa 4 on esitetty lannoituksen vaikutukset sadon koostumukseen. D-arvon kulmakerroin oli negatiivinen eli koko kesän painotettu D-arvo laski keskimäärin $0.1 \mathrm{~g} / \mathrm{kg} \mathrm{KA}$, kun typpilannoitusta lisättiin $1 \mathrm{~kg}$. Erityisesti kokonaan lannoittamatta jätettyjen 0-ruutujen D-arvo oli jonkin verran korkeampi kuin muiden näytteiden. Jos tarkastellaan vain lannoitettuja ruutuja, lannoituksen ja D-arvon välinen negatiivinen yhteys oli heikko. D-arvon lievä lasku typpilannoitusta lisättäessä voi johtua siitä, että ravinteiden puutteesta kärsineet kasvit eivät ole yhtä voimakkaasti lähteneet generatiiviseen kasvuun, jolloin huonommin sulavan korren osuus kasvustossa on voinut olla pienempi. Typpilannoituksen satoa lisäävän vaikutuksen takia sulavan orgaanisen aineen sato kuitenkin lisääntyi typpilannoituksen myötä selvästi (Taulukko 3). Rinteen (2000) yhteenvedon mukaan typpilannoituksen vaikutukset nurmirehun D-arvoon ovat olleet vähäisiä. Rehuntuotannossa on keskeistä tuottaa tasapainoisella lannoituksella riittävän suuri ja koostumukseltaan tasapainoinen sato.

Sadon raakavalkuaispitoisuus lisääntyi selvästi typpilannoitusta lisättäessä samoin kuin kalin ja fosforin pitoisuudet, joiden lannoitteen mukana annettu määrä niinikään lisääntyi, koska käytettiin seoslannoitteita. Fosforin, magnesiumin ja mangaanin pitoisuudet eivät kuitenkaan lisääntyneen nurmen jälkikasvussa. Mangaanin pitoisuuteen lannoitus ei vaikuttanut merkitsevästi myöskään sadossa keskimäärin. Kuparin ja sinkin pitoisuudet sadossa lisääntyivät lannoituksen lisäämisen myötä. Korkeat yksittäiset kalsiumpitoisuudet ovat nurmista, jotka sisälsivät puna-apilaa, sillä apilan kalsiumpitoisuus on huomattavasti korkeampi kuin nurmiheinien (vrt. MTT 2004).

Maalajeittain koelohkot luokiteltiin kolmeen ryhmään eli karkeat kivennäismaat, savimaat ja eloperäiset maat. Kivennäismaiden osuus oli noin 80 \% ja eloperäisten ja savimaiden kummankin noin $10 \%$. Karkeilla kivennäismailla typpikilolla saatiin $25.8 \mathrm{~kg} \mathrm{KA} / \mathrm{ha}$ (vakio $3244 \mathrm{~kg} / \mathrm{ha}$ ) kun vasteet savimailla ja eloperäisillä mailla olivat $20.4 \mathrm{~kg} \mathrm{KA} / \mathrm{ha} \mathrm{ja} 18.5 \mathrm{~kg} \mathrm{KA} / \mathrm{ha}$ (vakiot 3731 ja $4845 \mathrm{~kg} / \mathrm{ha}$ ).

Aineisto luokiteltiin pH:n mukaan eri luokkiin (luokat <6, 6-6.5 ja >6,5). Maan happamuuden osalta suurin ero satovasteessa ja vakion arvossa oli pH:n noustessa yli 6.5:n. 

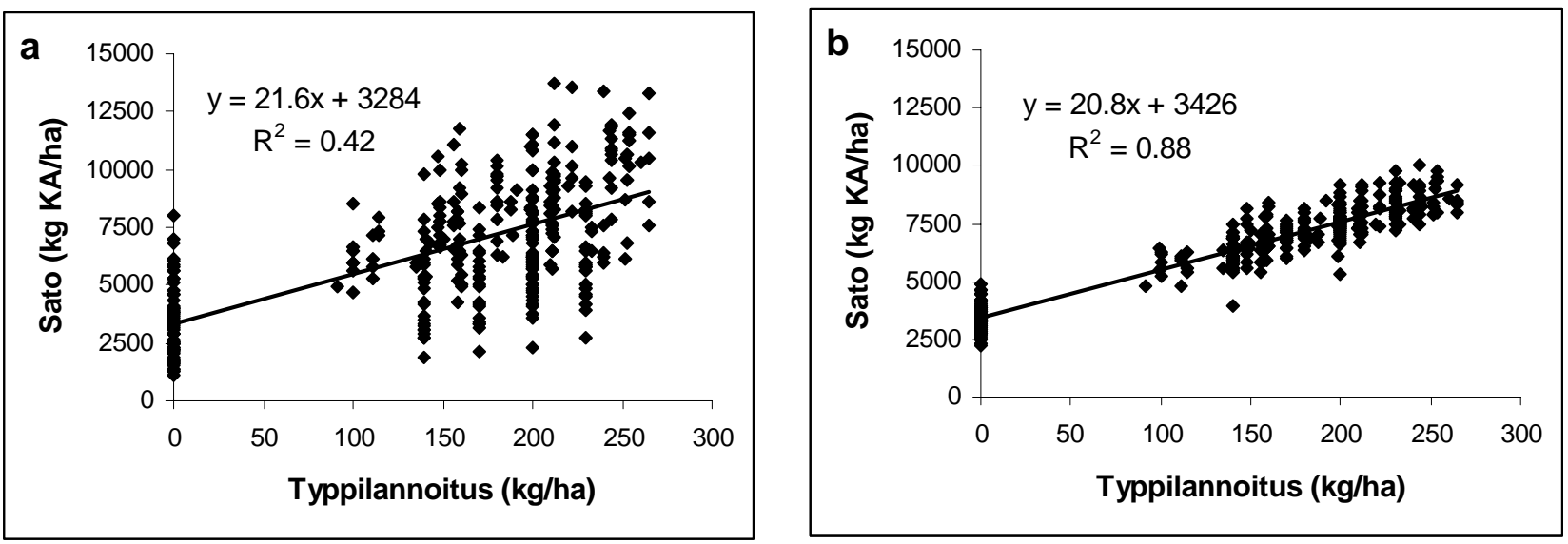

Kuva 1. Nurmen typpilannoituksen ja koko kesän yhteenlasketun kuiva-ainesadon ( $\mathrm{n}=336$ ) yhteys yksinkertaisella regressiomallilla (a) ja mixed-mallilla, jossa tila*vuosivaikutus on huomioitu (b).

\section{Johtopäätökset}

Tämän aineiston typpilannoituksen ja satotason yhteys tukee nurmien nykyisiä typpilannoitussuosituksia. Sadon määrän lisäksi typpilannoituksen lisääminen lisäsi myös useimpien kivennäis- ja hivenaineiden pitoisuuksia rehussa. Vaihtelu ruohonäytteiden kivennäis- ja hivenainepitoisuuksissa oli suurta, joten niiden analysointi ruokinnansuunnittelun pohjaksi on usein perusteltua. Lannoituskoeaineiston analysointi kokonaisuutena osoittautui hyödylliseksi tavaksi saada laskettua käyttökelpoisia lannoitusvasteita käytännön suositusten ja neuvonnan pohjaksi. Haasteena on mallintaa nurmen kasvu siten, että voitaisiin yhdistää D-arvo, lannoitus ja satotaso, jotta nurmituotantoa voitaisiin optimoida suhteessa ruokintaan ja pellon käyttöön.

\section{Kirjallisuus}

MTT 2004. Rehutaulukot ja ruokintasuositukset [verkkojulkaisu]. Jokioinen: Maa- ja elintarviketalouden tutkimuskeskus. Julkaistu 30.6.2004. Saatavissa: http://www.agronet.fi/rehutaulukot/

Rinne, M. 2000. Influence of the timing of the harvest of primary grass growth on herbage quality and subsequent digestion and performance in the ruminant animal. Helsingin yliopiston kotieläintieteen laitoksen julkaisuja 54. 42 p. + 5 liitettä. Väitöskirja. Saatavissa: http://ethesis.helsinki.fi/julkaisut/maa/kotie/vk/rinne.

Viljavuuspalvelu 2005. Tilastot. Hivenravinteet ProAgria-alueittain: koko maa. Saatavissa:

www.viljavuuspalvelu.fi 
Taulukko 2. Aineiston kuvailu.

\begin{tabular}{lccccc}
\hline & $\mathrm{n}$ & Keskiarvo & Keskihaj. & Minimi & Maksimin \\
\hline $\begin{array}{l}\text { Sadon määrä: } \\
\text { Kuiva-aine (kg/ha) }\end{array}$ & & & & & \\
$\quad$ Yhteensä & 336 & 6588 & 2739 & 1150 & 13749 \\
$\begin{array}{l}\text { 1. sato } \\
\text { 2. sato }\end{array}$ & 336 & 3391 & 1553.1 & 540 & 8447 \\
$\quad$ 1. sadon osuus & 336 & 3197 & 1565.3 & 380 & 8339 \\
Rakkavalkuainen (kg/ha) & 336 & 0.520 & 0.1139 & 0.248 & 0.849 \\
$\quad$ Yhteensä & 336 & 1030 & 503 & & \\
1. sato & 336 & 551 & 295.2 & 70 & 1363 \\
2. sato & 336 & 478 & 255.4 & 41 & 1294
\end{tabular}

Sadon koostumus:

D-arvo (g/kg KA)

Keskimäärin

1. sato

2. sato

160

160

160

Raakavalkuainen (g/kg KA)

Keskimäärin

1. sato

336

2. sato

336

336

Fosfori (g/kg KA)

Keskimäärin

321

1. sato

321

2. sato

326

Kalium (g/kg KA)

Keskimäärin

1. sato

2. sato

336

336

336

Magnesium (g/kg KA)

Keskimäärin

326

1. sato

326

2. sato

326

Kalsium /g/kg KA)

Keskimäärin

311

1. sato

311

2. sato

316

Natrium (g/kg KA)

Keskimäärin

1. sato

2. sato

336

336

336

Kupari (mg/kg KA)

Keskimäärin

1. sato

2. sato

311

311

Mangaani (mg/kg KA)

Keskimäärin

115

1. sato

2. sato

124

150

Sinkki (mg/kg KA)

Keskimäärin

1. sato

2. sato

310

310

316

Rauta (mg/kg KA)

Keskimäärin

1. sato

120

128

150

2. sato
66.4

68.0

64.9

152

158

148

3.1

3.2

3.1

29

29

29

1.9

1.7

2.1

4.0

3.3

4.8

0.23

0.22

0.24

7

7

7

49

44

56

32

32

31

100

88

106
2.42

2.64

3.29

58.2

55.0

55

75.1

75

30.9

36.9

36.0

66

233

$61 \quad 258$

$71 \quad 262$

0.41

2.2

5.0

0.46

0.58

2.2

4.7

5.4

4.51

4.78

5.69

17

39

43

46

0.51

1.0

4.0

0.47

0.8

4.1

0.70

0.9

5.2

1.12

2.1

10.8

0.80

1.7

6.3

1.72

2.2

15.0

0.149

0.03

1.19

0.138

0.03

0.87

0.204

0.02

1.8

1.6

12

1.8

13

13

150

21.3

$\begin{array}{ll}18 & 150 \\ 17 & 150\end{array}$

20.6

25.2

$\begin{array}{ll}18 & 150 \\ 17 & 150\end{array}$

$\begin{array}{lll}12.7 & 14 & 110\end{array}$

34.5

51

351

39.1

41

440

350 
Taulukko 3. Typpilannoituksen (kg/ha) vaikutus nurmen kuiva-aineen ja sulavan orgaanisen aineen satoon sekä sadon mukana korjattujen kivennäis- ja hivenaineiden määrään yhteensä sekä erikseen 1 . ja 2. sadossa.

\begin{tabular}{|c|c|c|c|c|c|c|c|c|}
\hline & Vakio & S.E. & P-arvo & $\begin{array}{l}\text { Kulma- } \\
\text { kerroin }\end{array}$ & S.E. & P-arvo & RSME & $\mathrm{R}^{2}$ \\
\hline \multicolumn{9}{|c|}{ Kuiva-aine (kg/ha) } \\
\hline Yhteensä & 3426 & 188.1 & $<.0001$ & 20.8 & 0.84 & $<.0001$ & 615.7 & 0.884 \\
\hline 1. sato & 1919 & 112.2 & $<.0001$ & 17.5 & 0.90 & $<.0001$ & 343.7 & 0.842 \\
\hline 2. sato & 1574 & 122.2 & $<.0001$ & 23.8 & 1.20 & $<.0001$ & 470.9 & 0.795 \\
\hline \multicolumn{9}{|c|}{ Sulava orgaaninen aine (kg/ha) } \\
\hline Yhteensä & 2783 & 170.9 & $<.0001$ & 14.2 & 0.78 & $<.0001$ & 429.2 & 0.881 \\
\hline 1. sato & 1563 & 112.6 & $<.0001$ & 12.1 & 0.92 & $<.0001$ & 245.5 & 0.831 \\
\hline 2. sato & 1299 & 119.4 & $<.0001$ & 15.6 & 1.14 & $<.0001$ & 323.4 & 0.803 \\
\hline \multicolumn{9}{|c|}{ Raakavalkuainen (kg/ha) } \\
\hline Yhteensä & 366 & 25.6 & $<.0001$ & 4.34 & 0.166 & $<.0001$ & 124.2 & 0.891 \\
\hline 1. sato & 198 & 13.2 & $<.0001$ & 4.16 & 0.192 & $<.0001$ & 75.1 & 0.863 \\
\hline 2. sato & 178 & 17.0 & $<.0001$ & 4.40 & 0.202 & $<.0001$ & 91.0 & 0.781 \\
\hline \multicolumn{9}{|c|}{ Fosfori (kg/ha) } \\
\hline Yhteensä & 10.2 & 0.67 & $<.0001$ & 0.0709 & 0.00302 & $<.0001$ & 2.15 & 0.879 \\
\hline 1. sato & 5.4 & 0.35 & $<.0001$ & 0.0663 & 0.00340 & $<.0001$ & 1.29 & 0.844 \\
\hline 2. sato & 5.0 & 0.44 & $<.0001$ & 0.0730 & 0.00385 & $<.0001$ & 1.58 & 0.765 \\
\hline \multicolumn{9}{|c|}{ Kalium (kg/ha) } \\
\hline Yhteensä & 86.1 & 5.55 & $<.0001$ & 0.710 & 0.0295 & $<.0001$ & 21.75 & 0.877 \\
\hline 1. sato & 47.2 & 2.98 & $<.0001$ & 0.626 & 0.0328 & $<.0001$ & 12.02 & 0.847 \\
\hline 2. sato & 40.8 & 3.64 & $<.0001$ & 0.782 & 0.0381 & $<.0001$ & 16.17 & 0.781 \\
\hline \multicolumn{9}{|c|}{ Magnesium (kg/ha) } \\
\hline Yhteensä & 5.5 & 0.41 & $<.0001$ & 0.0445 & 0.00261 & $<.0001$ & 1.51 & 0.853 \\
\hline 1. sato & 2.5 & 0.17 & $<.0001$ & 0.0373 & 0.00245 & $<.0001$ & 0.76 & 0.833 \\
\hline 2. sato & 3.1 & 0.31 & $<.0001$ & 0.0510 & 0.00346 & $<.0001$ & 1.33 & 0.691 \\
\hline \multicolumn{9}{|c|}{ Kupari (g/ha) } \\
\hline Yhteensä & 20.7 & 2.11 & $<.0001$ & 0.173 & 0.0098 & $<.0001$ & 6.52 & 0.825 \\
\hline 1. sato & 11.3 & 0.94 & $<.0001$ & 0.142 & 0.0081 & $<.0001$ & 4.15 & 0.705 \\
\hline 2. sato & 10.2 & 1.35 & $<.0001$ & 0.200 & 0.0150 & $<.0001$ & 5.75 & 0.649 \\
\hline \multicolumn{9}{|c|}{ Mangaani (g/ha) } \\
\hline Yhteensä & 219 & 31.8 & $<.0001$ & 1.17 & 0.118 & $<.0001$ & 65.7 & 0.666 \\
\hline 1. sato & 93 & 17.0 & $<.0001$ & 1.10 & 0.091 & $<.0001$ & 36.2 & 0.638 \\
\hline 2. sato & 115 & 14.1 & $<.0001$ & 1.31 & 0.169 & $<.0001$ & 40.0 & 0.639 \\
\hline \multicolumn{9}{|c|}{ Sinkki (g/ha) } \\
\hline Yhteensä & 91.6 & 9.03 & $<.0001$ & 0.786 & 0.037 & $<.0001$ & 34.42 & 0.775 \\
\hline 1. sato & 50.8 & 4.70 & $<.0001$ & 0.712 & 0.039 & $<.0001$ & 15.86 & 0.803 \\
\hline 2. sato & 43.3 & 5.27 & $<.0001$ & 0.832 & 0.053 & $<.0001$ & 28.39 & 0.566 \\
\hline
\end{tabular}


Taulukko 4. Typpilannoituksen (kg/ha) vaikutus D-arvoon, raakavalkuaisen, kivennäis- ja hivenaineiden pitoisuuksiin ruohossa keskimäärin ja erikseen 1. ja 2. sadossa.

\begin{tabular}{|c|c|c|c|c|c|c|c|c|}
\hline & Vakio & S.E. & P-arvo & $\begin{array}{l}\text { Kulma- } \\
\text { kerroin }\end{array}$ & S.E. & P-arvo & RSME & $\mathrm{R}^{2}$ \\
\hline \multicolumn{9}{|c|}{ D-arvo (g/kg KA) } \\
\hline Keskimäärin & 679 & 3.9 & $<.0001$ & -0.116 & 0.0159 & $<.0001$ & 7.0 & 0.652 \\
\hline 1. sato & 693 & 4.9 & $<.0001$ & -0.164 & 0.0336 & $<.0001$ & 6.9 & 0.532 \\
\hline 2. sato & 664 & 5.2 & $<.0001$ & -0.261 & 0.0360 & $<.0001$ & 13.0 & 0.411 \\
\hline \multicolumn{9}{|c|}{ Raakavalkuainen (g/kg KA) } \\
\hline Keskimäärin & 114 & 2.8 & $<.0001$ & 0.246 & 0.0135 & $<.0001$ & 10.4 & 0.789 \\
\hline 1. sato & 112 & 2.9 & $<.0001$ & 0.548 & 0.0236 & $<.0001$ & 14.4 & 0.748 \\
\hline 2. sato & 119 & 3.5 & $<.0001$ & 0.421 & 0.0376 & $<.0001$ & 14.6 & 0.560 \\
\hline \multicolumn{9}{|c|}{ Fosfori (g/kg KA) } \\
\hline Keskimäärin & 2.95 & 0.046 & $<.0001$ & 0.00137 & 0.000222 & $<.0001$ & 0.131 & 0.421 \\
\hline 1. sato & 2.83 & 0.043 & $<.0001$ & 0.004425 & 0.000383 & $<.0001$ & 0.174 & 0.567 \\
\hline 2. sato & 3.13 & 0.071 & $<.0001$ & -0.00016 & 0.000696 & 0.82 & 0.180 & -0.002 \\
\hline \multicolumn{9}{|c|}{ Kalium (g/kg KA) } \\
\hline Keskimäärin & 25.2 & 0.39 & $<.0001$ & 0.0254 & 0.00201 & $<.0001$ & 1.76 & 0.581 \\
\hline 1. sato & 25.1 & 0.42 & $<.0001$ & 0.0486 & 0.00370 & $<.0001$ & 2.04 & 0.537 \\
\hline 2. sato & 25.6 & 0.52 & $<.0001$ & 0.0507 & 0.00567 & $<.0001$ & 2.74 & 0.342 \\
\hline \multicolumn{9}{|c|}{ Magnesium (g/kg KA) } \\
\hline Keskimäärin & 1.67 & 0.066 & $<.0001$ & 0.00122 & 0.000257 & $<.0001$ & 0.146 & 0.320 \\
\hline 1. sato & 1.39 & 0.060 & $<.0001$ & 0.00305 & 0.000361 & $<.0001$ & 0.155 & 0.441 \\
\hline 2. sato & 2.04 & 0.083 & $<.0001$ & 0.00084 & 0.000720 & 0.2475 & 0.303 & 0.009 \\
\hline \multicolumn{9}{|c|}{ Kupari (mg/kg KA) } \\
\hline Keskimäärin & 6.01 & 0.225 & $<.0001$ & 0.00665 & 0.001101 & $<.0001$ & 0.665 & 0.400 \\
\hline 1. sato & 5.94 & 0.193 & $<.0001$ & 0.01118 & 0.001673 & $<.0001$ & 0.850 & 0.259 \\
\hline 2. sato & 6.11 & 0.288 & $<.0001$ & 0.01558 & 0.003238 & $<.0001$ & 1.017 & 0.262 \\
\hline \multicolumn{9}{|c|}{ Mangaani (mg/kg KA) } \\
\hline Keskimäärin & 51.1 & 5.48 & $<.0001$ & 0.0099 & 0.01557 & 0.5286 & 4.73 & 0.019 \\
\hline 1. sato & 37.5 & 3.52 & $<.0001$ & 0.1088 & 0.02824 & 0.0006 & 5.47 & 0.429 \\
\hline 2. sato & 63.2 & 5.73 & $<.0001$ & -0.0580 & 0.03738 & 0.1299 & 7.26 & 0.090 \\
\hline \multicolumn{9}{|c|}{ Sinkki (mg/kg KA) } \\
\hline Keskimäärin & 26.0 & 0.95 & $<.0001$ & 0.0369 & 0.00465 & $<.0001$ & 3.51 & 0.421 \\
\hline 1. sato & 25.5 & 0.93 & $<.0001$ & 0.0778 & 0.00761 & $<.0001$ & 3.33 & 0.524 \\
\hline 2. sato & 26.1 & 1.12 & $<.0001$ & 0.0646 & 0.01179 & $<.0001$ & 5.78 & 0.158 \\
\hline
\end{tabular}

